\title{
Orientation of rainbow trout (Salmo gairdneri) in normal and null magnetic fields
}

\author{
G. L. Chew ${ }^{1}$ AND G. E. Brown \\ Department of Psychology, The University of Lethbridge, Lethbridge, Alta., Canada TIK $3 M 4$ \\ Received November 30, 1987
}

Chew, G. L., and Brown, G. E. 1989. Orientation of rainbow trout (Salmo gairdneri) in normal and null magnetic fields. Can. J. Zool. 67: 641-643.

In the absence of distinct visual or olfactory cues, adult and juvenile rainbow trout (Salmo gairdneri) showed preferred orientation in the presence of a normal magnetic field. In contrast, fish tested in a null magnetic field showed no directed orientation. These results were obtained in both the presence and absence of a slight $(12-\mathrm{cm} / \mathrm{s})$ circular water current. These findings indicate that nonanadromous salmonids, like anadromous forms, are capable of sensing magnetic cues during certain types of spatial activity.

Chew, G. L., et Brown, G. E. 1989. Orientation of rainbow trout (Salmo gairdneri) in normal and null magnetic fields. Can. J. Zool. 67 : 641-643.

En l'absence de stimulus visuels ou olfactifs sensibles, les Truites arc-en-ciel (Salmo gairdneri) adults et juvéniles s'orientent de façon particulière en présence d'un champ magnétique normal. En revanche, les poissons mis en présence d'un champ magnétique nul ne manifestent aucune orientation définie. Ces résultats ont été obtenus avec ou sans courant d'eau (courant circulaire de $12 \mathrm{~cm} / \mathrm{s}$ ). Ces données indiquent que les salmonidés non anadromes aussi bien que les formes anadromes sont sensibles à des stimulus de nature magnétique au cours de certains types d'activité spatiale.

[Traduit par la revue]

Several fish species are believed to use geomagnetic cues in orientation and navigation (Smith 1985). These include the American eel (Anguilla rostrata) (McCleave and Power 1978; Rommel and McCleave 1973), yellowfin tuna (Thunnus albacares) (Walker 1984), various sharks and rays (Kalmijn 1982), as well as several species of salmon. In this last group it is known that sockeye salmon (Oncorhynchus nerka) (Quinn 1980; Quinn et al. 1981; Quinn and Brannon 1982), chum salmon (Oncorhynchus keta) (Quinn and Groot 1983), the Atlantic salmon (Salmo salar) (McCleave and Power 1978; Rommel and McCleave 1973; Varanelli and McCleave 1974), and possibly the chinook salmon (Oncorhynchus tshawytscha) (Kirschvink et al. 1985) are capable of using the earth's magnetic field in orientation and navigation.

This paper extends the investigation of geomagnetic sensing in salmonids by examining the orientation of juvenile and adult rainbow trout (Salmo gairdneri) in normal and null magnetic fields. If $S$. gairdneri use magnetic sensing in orientation, we predicted they would $(i)$ show preferred orientation in an arena in the presence of a normal (earth strength) magnetic field and (ii) show random orientation in a null magnetic environment. As the ontogenetic properties are also poorly understood, we tested both under-yearling and adult fish to investigate possible age differences in the ability to orient in normal and null magnetic conditions.

In so doing, we hoped to establish whether nonanadromous salmonid forms are capable of using geomagnetic cues in spatial behaviour, i.e., orientation, as well as to provide some basic characterization of the developmental aspects of this ability.

\section{Methods}

Sixty-four Mt. Lassen strain rainbow trout, 32 adults (age $>1$ year) and 32 juveniles (age approximately 6 months), of undetermined sex were used. They were obtained from a commercial breeder and housed at the aquaculture facilities at Lethbridge Community College under natural lighting conditions. The fish were maintained in aerated $12^{\circ} \mathrm{C}$ water in circular flow drum tanks (Frigid Units model RT-430)

${ }^{1}$ Author to whom correspondence should be addressed. and were hand-fed twice daily with trout pellets (Rangen Inc.). They were held for 2 weeks prior to testing.

There were eight groups of eight fish each. Each group represented one of the following possible combinations: geomagnetic environment (normal or null), current flow (present or absent), and age (juvenile or adult). On the day of testing, fish were transported to either the University of Lethbridge remote animal facility (normal geomagnetic field condition) or to the amagnetic laboratory of the federal Lethbridge Agricultural Research Station (null geomagnetic field condition). These facilities were comparable in terms of distance from the holding tanks as well as in terms of ambient sound and temperature levels. Testing was done indoors in both cases in rooms of similar size; the only difference between the test chambers was that the amagnetic room was shielded from the local magnetic field, whereas the remote compound room was not.

In both magnetic and amagnetic conditions, the test arena was a $1.2-\mathrm{m}$ diameter monocolour (blue) plastic pool. The same pool was used throughout this study. In was filled with fresh water to a depth of $20.3 \mathrm{~cm}$ at $12^{\circ} \mathrm{C}$. An opaque, green plastic four-ply drop sheet covered the pool so that it was bathed in dim, diffuse, uniform illumination. Light intensity at the surface of the water was less than $30 \mathrm{~lx}$ (cosine corrected) for all conditions (General Electric model 214 light meter). In the four "current-present"' groups, a small $(12 \mathrm{~cm} / \mathrm{s})$, counterclockwise constant current was produced by a Fluval aquarium pump in the remaining four "current-absent'-' groups, the pump was turned off but left in the pool. The pump was randomly positioned between trials in both current conditions to control for its possible use as a visual marker or shelter. To minimize the possible confounding effects of olfactory cues in the pool, water was partially changed and thoroughly stirred between trials.

The amagnetic room was constructed of a nickel-silver alloy $(\mathrm{Mu}$ metal) (Bozorth 1964) and was lined with grounded copper strips to produce a null magnetic field within the room interior. The absence of a field was such that a compass needle remained in any direction in which it was aimed. By comparison, the compass heading under normal geomagnetic conditions at the remote facility was $338^{\circ}$ where a $0^{\circ}$ heading was defined as due north.

Subjects were placed singly in the pool and were left undisturbed for $20 \mathrm{~min}$ to allow for acclimation, during which time the subject adopted a stationary (hovering) position. The facing position (orientation) held at the end of this time was recorded independently by two observers located at randomly selected points around the pool perimeter. The observers were unaware of the direction of the local magnetic field outside the amagnetic chamber. Recordings were made 
MAGNETIC
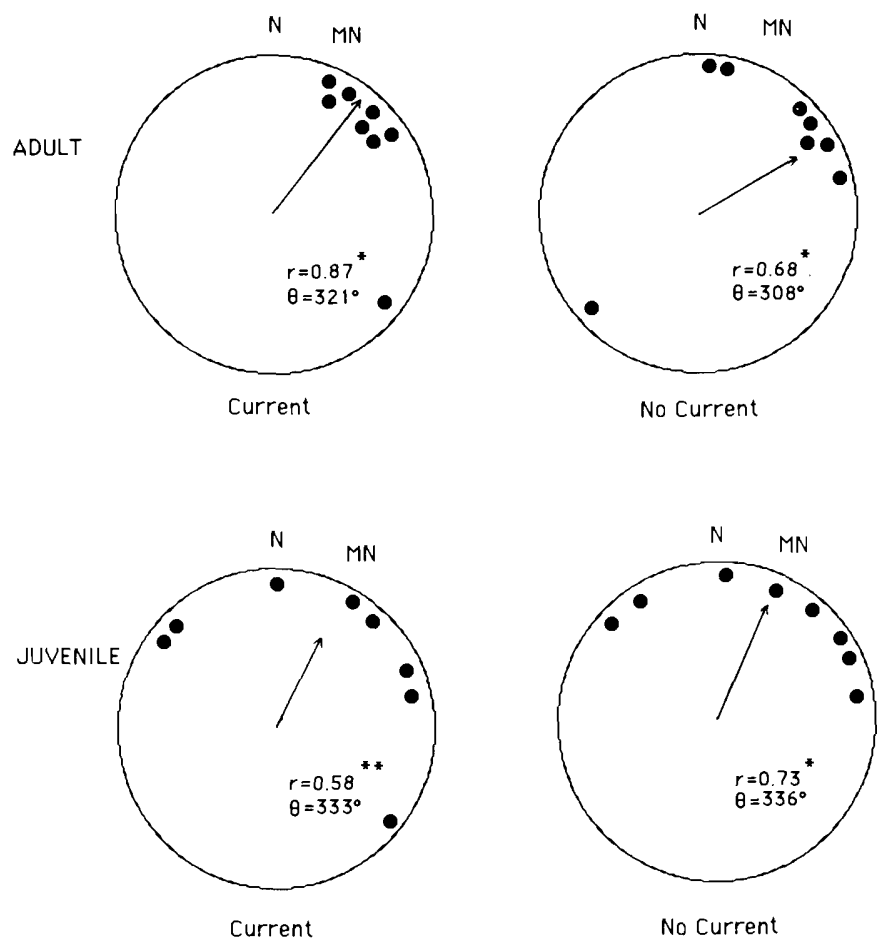

FIG. 1. Orientation of $S$. gairdneri adults and juveniles in a normal magnetic field in the presence and absence of a $12 \mathrm{~cm} / \mathrm{s}$ current. $\mathrm{N}$, geographic north; $\mathrm{MN}$, magnetic north; $r$, Rayleigh statistic; $\theta$, heading relative to due north; ${ }^{*}, p<0.05 ;^{* *}, p=0.06$.

by denoting orientation as a vector on a unit circle to within the nearest degree; inter-rater reliability was $94 \%$. Each fish was tested only once.

\section{Results}

Fish in those groups tested in the normal magnetic field condition clearly showed preferred orientations. Regardless of age or the presence or absence of a current, the preferred orientations were towards the northeast, i.e., in approximate alignment with the directon of the geomagnetic field. The orientation of each fish along with the mean heading are presented in Fig. 1. Also included for each group is the Rayleigh statistic, $r$, which is an index of the degree of departure of each group's distribution from a uniform, random distribution (Batschelet 1981). All $r$ 's showed statistically significant departures from the uniform case at $p<0.05$ except for the juvenile, current-present condition $(r=0.58, p=0.06)$.

It is further noted the mean angular deviation (Batschelet 1981) was smaller for adults than for juveniles. The same is true for both the current-present condition $\left(s_{\text {adult }}=11.5 \mathrm{vs}\right.$. $\left.s_{\text {juvenile }}=52.7\right)$ and the current-absent condition $\left(s_{\text {adult }}=28.1\right.$ vs. $s_{\text {juvenile }} 37.2$ ).

In contrast to the normal field groups, the distributions of those fish in each of the four groups tested in the null magnetic field condition were statistically indistinguishable from randomness (all $p>0.05$ ). These results are presented in Fig. 2 .

\section{Discussion}

These results suggest that rainbow trout, like some of the anadromous salmonids, are able to use geomagnetic informa-

\section{AMAGNETIC}
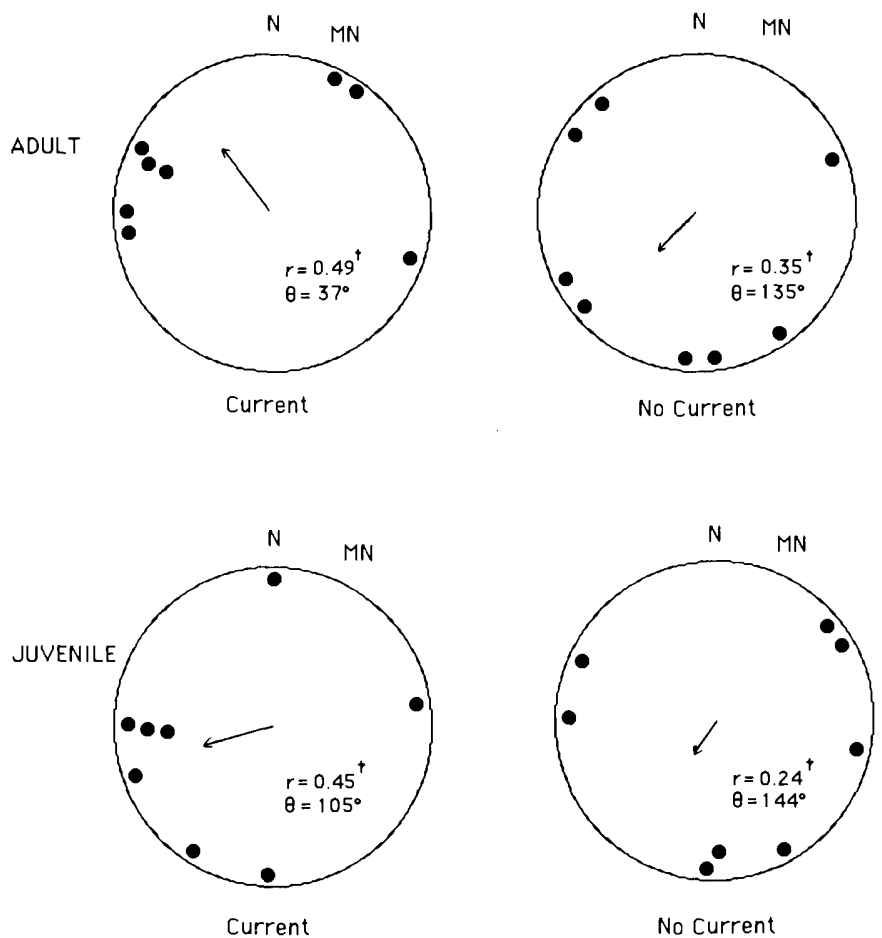

FIG. 2. Orientation of adult and juvenile $S$. gairdneri under null magnetic field conditions in the presence and absence of a $12 \mathrm{~cm} / \mathrm{s}$ current, $\mathrm{N}$, geographic north; $\mathrm{MN}$, magnetic north; $r$, Rayleigh statistic; $\theta$, heading relative to due north; $\dagger, p>0.05$.

tion in orientation. Under uniform lighting and olfactory conditions and slight constant current, rainbow trout juveniles and adults tended to adopt stations that tracked the horizontal component of the local magnetic field. In contrast, in the absence of such magnetic cues, the orientations appeared to be random.

The tracking of the field is not perfect, however. Of the adults whose orientations were less variable than those of the juveniles, one was clearly not aligned with the ambient magnetic field (see Fig. 1; adult, current condition), and one was aligned in a direction opposing (i.e., facing into) the horizontal component of the magnetic field (see Fig. 1; adult, no-current condition). Moreover, it is noted that the observed mean orientation of both adults and juveniles are only imperfectly aligned with magnetic north. These findings suggest that even under conditions where visual and olfactory cue information is restricted, orientation may involve more than just the detection and passive alignment with the magnetic field. That is, the information provided by the sensation and perception of magnetic cues may be processed at higher, more central levels of the nervous system, as is the case with other spatial information cues in other species (Sutherland and Dyck 1984; Sutherland et al. 1982).

The greater variation in juvenile relative to adult orientation may be explained with the magnetic hypothesis for homing in fish (Kirschvink and Gould 1981; Kirschvink et al. 1985). That is, if the observed orientation behaviour is based on the nervous transduction of the alignment vectors of magnetite particles located within the trout (possibly the head), and if such magnetite deposition is the result of metabolic activity occurring throughout the life history of the trout, then the 
greater ability of adults to track the magnetic field may simply be the result of greater sensitivity or resolving power owing to the presence of a greater concentration of the mineral. More simply, adults are more accurate than juveniles in magnetismbased orientation because they have more magnetite.

The following questions arise from the current work: (i) Aside from direction, it is not known what other parameters of the magnetic field (e.g., intensity, flux, inclination, or some combination) the trout were using in their orientation. (ii) It is not known what priority magnetically guided orientation has relative to visually or olfactory guided orientation. (iii) The extent to which this magnetic sensitivity is found in other nonanadromous salmonids remains unknown. (iv) With respect to $S$. gairdneri specifically, it is possible that the anadromous form (i.e., steelhead trout) may also exhibit some magnetic sensing ability, possibly for use during high-seas migration as has been suggested for $O$. nerka (Quinn 1980). (v) The sensory and neural basis of magnetically based orientation in nonanadromous salmonids remains unknown. Present work is addressing this last question by attempting to delineate the psychophysical and neuroanatomical parameters of this geomagnetic sense.

\section{Acknowledgements}

The authors thank R. Beck, W. Sharp, and Drs. U. Pittman, L. Stebbins, and W. Lindwall for their assistance. Drs. L. Delude, R. Sutherland, and R. Wong, and anonymous reviewers made helpful comments on early drafts of this paper. This work, supported by the Alberta Heritage Fund for Medical Research, was undertaken while G.L.C. was a Natural Sciences and Engineering Research Council of Canada (NSERC) Postdoctoral Fellow and G.E.B. was an NSERC Summer Scholarship student.

Batschelet, E. 1981. Circular statistics in biology. Academic Press, Toronto.

Bozorth, R. M. 1964. Ferromagnetism. Van Nostrand Press, Princeton, NJ.
KalmiJn, A. J. 1982. Electrical and magnetic field detection in elasmobranch fishes. Science (Washington, DC), 218: 916-918.

KiRSCHVINK, J. L., and GoulD, J. L. 1981. Biogenic magnetite as a basis for magnetic field detection in animals. Biosystems, 13: $181-201$.

Kirschvink, J. L., Walker, M. M., Chang, S-B., Dizon, A. E., and Peterson, K. A. 1985. Chains of single-domain magnetite particles in chinook salmon, Oncorhynchus tshawytscha. J. Comp. Physiol. A Sens. Neural Behav. Physiol. 157: 375-381.

McCleave, J. D., and Power, J. H. 1978. Influence of weak electric and magnetic fields on turning behaviour in elvers of the American eel Anguilla rostrata. Mar. Biol. (Berlin), 46: 29-34.

QuinN, T. P. 1980. Evidence for celestial and magnetic compass orientation in lake migrating sockeye salmon fry. J. Comp. Physiol. A Sens. Neural Behav. Physiol. 137: 243-248.

Quinn, T. P., and Brannon, E. L. 1982. The use of celestial and magnetic cues by orienting sockeye salmon smolts. J. Comp. Physiol. A Sens. Neural Behav. Physiol. 147: 547-552.

QuinN, T. P., and Groot, C. 1983. Orientation of chum salmon (Oncorhynchus keta) after internal and external magnetic field alteration. Can. J. Fish. Aquat. Sci. 40: 1598-1606.

Quinn, T. P., Merrill, R. T., and Brannon, E. L. 1981. Magnetic field detection on sockeye salmon Oncorhynchus nerka. J. Exp. Zool. 217: $137-142$.

Rommel, S. A., and McCleave, J. D. 1973. Sensitivity of American eels (Anguilla rostrata) and Atlantic salmon (Salmo salar) to weak electric and magnetic fields. J. Fish. Res. Board Can. 30: $657-663$.

SMITH, R. J. F. 1985. The control of fish migration. Springer-Verlag, New York.

Sutherland, R. J., and Dyck, R. H. 1984. Place navigation by rats in a swimming pool. Can. J. Psychol. 38: 322-347.

Sutherland, R. J., Whishaw, I. Q., and KolB, B. 1982. Spatial mapping: definitive disruption by hippocampal or medial frontal cortical damage in the rat. Neurosci. Lett. 31: 271-276.

Varanelli, C. C., and McCleave, J. D. 1974. Locomotor activity of Atlantic salmon parr (Salmo salar L.) in various light conditions and in weak magnetic fields. Anim. Behav. 22: 178-186.

WALKER, M. M. 1984. Learned magnetic field discrimination in yellowfin tuna, Thunnus albacares. J. Comp. Physiol. A Sens. Neural Behav. Physiol. 155: 673-679. 